\title{
A Corponegritude no Espaço Escolar - um processo cênico-pedagógico
}

\author{
Jonas de Lima Sales \\ Universidade de Brasília - UnB, Brasília/DF, Brasil \\ E-mail: jonassales1@gmail.com
}

\section{Resumo}

Abstract

Mostra-se aqui uma proposta pedagógica para processos criativos em artes cênicas. Tem como referência as reflexões que permeiam os saberes sobre culturas de matriz africana para procedimentos de trabalho técnico e poético do artista cênico. Danças afro-brasileiras são condutores para o processo de trabalho que aqui se apresenta promovendo ao aluno/artista a descoberta da Corponegritude, conceito desenvolvido para este trabalho.
A pedagogical proposal for criative processes in performing arts is shown here. It has reference to the reflections that permeate the knowledge about the culture of African origin for technical and poetic work procedures of the scenic artist. Afro-Brazilian dances are guiding to the work process presented here promoting the student/artist discovery of Corponegritude, concept developed for this work.
Palavras-chave

Corporeidade. Tradição. Afro-brasileiro. Técnica. Poética.

\section{Keywords}

Corporeity. Tradition. Afro-Brazilian. Technique. Poetic. 
Nas últimas décadas, mudanças ocorreram no ensino de Arte do currículo brasileiro. Foi constituído os Parâmetros Curriculares Nacionais (PCN) a partir da Lei 9.394/96, o qual aponta o conhecimento artístico como articulação de sentidos, fruição e produção, além de inserir temas transversais como a pluralidade cultural, ampliando a atuação dessa área do saber e sentir. Implantou-se também a lei 10.639/03 e sequentemente a 11.645/08 em que incluem a obrigação da história e culturas africana, afro-brasileira e indígena no currículo escolar. Com isso, surgiu uma perspectiva de que possam emergir novos processos e metodologias aplicados em nossos espaços de educação.

Desse modo, torna-se fundamental reflexões e ações a partir da ideia de que a produção artística deve ser interpretada à luz de seu contexto cultural (PARSONS, 1998). Diante dessa ideia, verifica-se a premência de uma constante revisão nas práticas pedagógicas no sentido da construção de caminhos que redirecionem e inspirem os novos saberes para esse campo epistemológico. Para tanto, faz-se necessário percorrer um caminho de sólidas conquistas e evidentes lacunas que o sistema de ensino da Arte, em destaque as Artes cênicas, nos legou no decorrer de sua história. Portanto, faz-se pertinente avivar a consciência de que a produção artística pode residir não só em espaços oficiais como museus e teatros, mas também em praças, calçadas, terreiros, bares, dentre outros locais. Nesta amplidão de espaços, permite-se então, novas percepções referentes às produções e a seus respectivos elementos estéticos, suscitando novos saberes e impulsionando os fazeres artísticos na contemporaneidade.

Ao longo de meu percurso de aprendizado e compartilhamento de saberes, acredito que a busca pela compreensão do objeto artístico por meio da leitura dos elementos estéticos que o compõem, suscita um processo de criação e/ou reelaboração artística. A partir da compreensão instaurada com esses fenômenos estético-artísticos, pode-se dar a releitura ou produções como fruto de inspirações vindo destes. Desse modo, promovendo novos direcionamentos para a formação de estéticas e produção de arte pelo interlocutor/artista. O interesse nessa discussão é mostrar uma Proposta de Processo Cênicopedagógico, resultante de uma pesquisa realizado com alunos/artistas do curso de artes cênicas da Universidade de Brasília (UnB). Com isso, desejase contribuir com os estudos no campo do saber artístico inseridos em espaços de educação, tendo como elementos de inspirações estéticas e artísticas, expressões de artes da tradição afro-brasileira.

Refletindo sobre possíveis diálogos entre formas estéticas de culturas tradicionais e o artista cênico em seu processo de criação, resgato a proposta estabelecida pela Lei 10.639/03. Em seu parágrafo $2^{\circ}$, esta lei enfatiza que esse conteúdo deve ser ministrado no âmbito de todo o currículo escolar. Destaco então, nas disciplinas de linguagens artísticas em especial. Esses conteúdos são de fundamental importância para a formação cultural de um cidadão conectando-o com a história ancestral dos povos africanos que aqui chegaram. A respeito desses conteúdos no ambiente escolar, as professoras Ribeiro e Gonçalves enfatizam:

A escola exerce um papel fundamental como difusora desse acervo cultural, transmissora da cultura, tanto nacional quanto étnica, valorizando a diversidade e a afrobrasilidade que existe em todos os brasileiros. Uma escola onde todos os saberes se equivalem, sem hierarquias ou valoração diferenciada. (RIBEIRO; GONÇALVES, 2012, p. 36).

Fomentando esse campo de discussão e buscando a valoração e a não hierarquia de culturas, trago esse assunto por considerar sua importância no espaço educacional. Percebo a necessidade de não abafar esse tema nas diversas instâncias do aprendizado do sujeito, visto que, atualmente, estamos em um momento em que a sociedade se volta para a afirmação de culturas invisibilizadas.

Questionar e refletir sobre essas culturas que se constituem espalhadas em nosso tão extenso território, mostra-se no patamar de grande importância para a formação do sujeito em contraponto ao 
discurso enraizado de culturas dominantes ao longo de nosso processo histórico. Com isso, considero fundamental conhecer a Arte advinda do povo e, em especial, as de matrizes negras, por apresentarem estéticas e históricos próprios. Faz-se necessário visibilizar esse assunto não apenas nas instituições de ensino básico, como também nas de ensino superior, nas organizações sociais, em comunidades, etc. As marcas trazidas nessas expressões constituem base essencial para o aprendizado cidadão. Elas carregam traços da memória que aqui chegaram com os nossos ascendentes, em destaque os africanos, e que se perpetuaram até os dias de hoje. Nossas expressões culturais são muitas e é reflexo de uma sociedade diversa em um país de grandiosa extensão territorial.

Considerando essa diversidade, encontros acontecem, agregações de saberes, modificações em traços e características dessas expressividades culturais, surgem novos formatos em suas realizações e vão continuando sua existência a partir dessa dinâmica pertencente a cultura humana. No entanto, por mais que existam os hibridismos provenientes de conjunções de diversas culturas em nosso país, percebe-se que as matrizes dos povos negros africanos estão visivelmente presentes em eventos de cunho artístico-cultural brasileiro como Maracatus, Capoeira, Jongo, Congadas e outros. Por meio de musicalidades, oralidades e corporeidades, são fontes importantes de saberes à formação acadêmica e cidadã de sujeitos aprendizes.

Ao cogitar sobre tal situação, percebo que o caminho para promover reflexões e, por conseguinte, constituir saberes, não poderia ser outro que não o de provocar a experimentação corpórea dessas histórias de africanidades e negritudes contidas nas danças e folguedos tradicionais do Brasil. Avalio que a provocação para que haja a constituição de saberes nesse campo do movimento expressivo do corpo, tem que passar por sensações físicas, emocionais e sensíveis, despertando a aesthesis ${ }^{1}$. Dessa forma, propiciando ao sujeito partícipe dessa

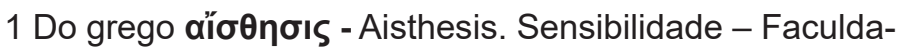
de do sentir - compreensão pelos sentidos. vivência, deixar-se impregnar pelos processos corporais que as práticas com expressões tradicionais do povo possibilitam. Com isso, espera-se desvincular essas manifestações cênicas tradicionais das condições que foram traçadas ao longo de nossa história como sendo exótico ou de menor valor. Pois, ao pensar dessa maneira, estou considerando que;

Conhecer as origens é fundamental para a ampliação da consciência social e histórica do povo brasileiro. É necessário também questionar as distorções geradas no imaginário social pela hegemonia do pensamento social das elites, que nega ou menospreza o aporte de matrizes africana na formação da nacionalidade. (PEREIRA, 2012, p. 17).

Neste sentido, para corroborar com a compreensão das expressões da cultura de tradição afro-brasileira, ver-se que ler e compreendê-las requer um conhecimento dos códigos que as constituem. Portanto, devem-se levar em consideração alguns aspectos que sustentam a construção interpretativa os quais são intrínsecos ao leitor e partícipe da expressão de Arte, tais como o contexto social e/ ou cultural e lembranças já vivenciadas. Sobre esses aspectos, reforça Pillar (1999, p. 13): "Assim, há uma construção de conhecimentos visuais. O olhar de cada um está impregnado com experiências anteriores, associações, lembranças, fantasias, interpretações, etc". Acrescento que para a leitura e aprendizado sobre as formas de Arte que apresentam matrizes africanas contidas em nossas tradições culturais, a vivência corporal mostra-se propícia, visto que, pelo corpo, saberes são apreendidos e registrados por meio de suas experiências.

O papel da escola, dentre outros, é o de propiciar oportunidades ao educando para que ele possa também compreender as produções artísticas e os elementos estéticos que as constituem, considerando que

Repensar o alcance e o significado da atividade artística e o campo epistemológico e relacional da estética implica considerar o que é necessário, para que a experiência estética seja, ao mesmo tempo, um fator de emoção, sentimento, e num nível 
mais complexo, reflexão, tanto sobre a arte, como sobre a vida. (MEIRA, 2001, p. 128).

Sendo assim, A experiência estética que leva à compreensão da produção artística, passa pelo entendimento da forma e da plasticidade composta no objeto que vem contida de simbologias. Assim, promove a interação entre o artista e o apreciador. Cada sujeito que aprecia e vivencia uma expressão da tradição do povo, constrói interpretações segundo seus próprios significados, tanto individuais quanto sociais. À vista disso, possibilita a projeção de saberes e consequentemente vem a contribuir para a elaboração de produções estético-artísticas.

Considerando o espaço da educação, os PCN reconhecem a produção artística como pertencente à área de conhecimento da Arte e, consequentemente, com elementos conceituais que possibilitam estar em igualdade com as demais áreas de pesquisa científica.

A manifestação artística tem em comum com o conhecimento cientifico, técnico ou filosófico seu caráter de criação e inovação. Essencialmente, o ato criador, em qualquer dessas formas de conhecimento, estrutura e organiza o mundo, respondendo aos desafios que dele emanam, num constante processo de transformação do homem e da realidade circundante. O produto da ação criadora, a inovação, é resultante do acréscimo de novos elementos estruturais ou da modificação de outros. Regido pela necessidade básica de ordenação, o espírito humano cria, continuamente, sua consciência de existir por meio de manifestações diversas. (PARÂMETROS CURRICULARES NACIONAIS, 1996, p. 33).

Portanto, criação e recriação a partir do reconhecimento da Arte por meio de suas manifestações, estão respaldadas por leis específicas, integrando uma conquista da qual não se pode permitir uma desestruturação. O que se pode sugerir é, antes de tudo, o aperfeiçoamento dessa proposta.

Atualmente, pensando de forma ampla, os educandos ainda não possuem grandes oportunidades de estarem em contato com produções artísticas que partam de experiências adquiridas dentro do ambiente escolar. Isto se dá, visto que, na maioria das instituições de ensino, não encontramos quadro docente suficiente e qualificado que permita uma sistemática de ensino sobre culturas afro-brasileira e africana de modo eficiente. Lamentavelmente, ver-se uma não organização de secretarias de educação em fomentar a implementação do ensino de Arte como projetado por lei, bem como a abertura de cursos de formação continuada para professores. Com isso, forma-se uma grande lacuna em nosso corpo docente e não temos um número desejável de professores que seja capaz de possibilitar a aproximação contextualizada do educando com a produção artística, construindo o entendimento à luz do seu contexto sociocultural. Este problema institucional torna-se pauta para a luta constante no que diz respeito ao ensino de Arte em nossas instituições.

No caminho das conquistas do ensino de Arte ao longo da nossa história, percebe-se uma despreocupação no que se refere ao reconhecimento da importância dos conteúdos artísticos e estéticos no universo das significações de negritude presentes em nossa cultura. Analiso que esta despreocupação é em virtude desses conteúdos educativos não serem vistos como prioridade e fundamental na contribuição do processo de aprendizado do sujeito. A cultura artística afro-brasileira ainda é vista pelos espaços de ensino como culturas menores, exóticas e folclorizadas, em volta de preconceitos cristalizados na história, acentuando assim, um elitismo do conhecimento. Diante disso, dificulta-se também a escolha dos espaços e materiais necessários para que se desenvolvam atividades nesta área do conhecimento no ambiente escolar. Lamentavelmente, percebe-se que há uma discriminação dos conteúdos que estão presentes nas expressões artísticas de raízes africanas exploradas nas disciplinas de linguagens artísticas. Em grande parte das instituições de ensino, infelizmente, o fazer artístico ainda está vinculada como reforço e apoio para outras áreas de conhecimento do currículo escolar ou presente nos eventos da instituição, refletindo assim, um colonialismo do saber.

Ao trazer para o centro da discussão a cultura 
afro-brasileira em diversos ambientes sociais formais ou informais, expõe-se múltiplas manifestações artísticas que trazem elementos de matrizes culturais de uma negritude fortalecida ao longo da história do Brasil. Percebe-se nessas expressões de cultura, uma corporeidade que reflete signos e sentidos específicos de grupos étnicos advindos das regiões africanas como Congo, Gana, Costa do Marfim, Angola, Moçambique dentre outros que chegaram a solos americanos, principalmente no período de colonização de nosso país - Brasil (SALES, 2015). Desta maneira, esses grupos étnicos contribuíram para uma estética pontual que fundamenta diversas linguagens artísticas como as danças, músicas e diversos folguedos espalhados nas expressões tradicionais do povo em que se fezl fazem presentes no Brasil. Tais manifestações são elementos de valorosa contribuição para se construírem processos de aprendizagens que, em sua sistematização, possam colaborar para a constituição de saberes a respeito das expressões dessas culturas africanas incorporadas nas comunidades brasileiras.

Em nossas instituições de Artes que possuem pretensões de formar sujeitos sensíveis para o movimento corporal em cena, geralmente busca-se uma educação que conduz os envolvidos para reflexões que os possibilitem instrumentalizações técnicas e que possa despertar a sensibilidade para suas elaborações estético-artísticas. Nessa perspectiva, temos o corpo como um caminho para despertar um sujeito crítico e criativo. Desse modo, trazer a temática da negritude para a cena aponta possibilidades para que essa discussão seja vivenciada e aprendida no corpo como fator propulsor para descobertas, reflexões e discursos na atualidade.

O sujeito em situação de cena é resultado de uma construção de saberes que pressupõe uma determinada organização destes. Ou seja, o artista em cena traz consigo técnicas apreendidas em seu treinamento, bem como elementos do conhecimento adquirido em sua formação sociocultural organizadas a partir dos desejos pertinentes à elaboração de seu trabalho estético artístico. Os conhecimentos técni- cos e poéticos adquiridos podem agregar positivamente para as elaborações de propostas artísticas relacionadas as Artes da cena, conduzindo para novas concepções e consciência de si mesmo e do outro. Penso que, uma educação artística para a cena contemporânea, perpassa pela formação de um aluno/ artista, seja no ambiente escolar ou fora dos muros da escola, que seja um corpo "de e em" movimento, agente das transformações do mundo em que habita.

Neste sentido, apresento uma proposta que visa viabilizar a descoberta e vivência de uma cultura de negritude a partir de práticas cênicas-dançantes, contribuindo para os processos reflexivos e criativos na formação dos alunos/artistas da cena, em qualquer nível de ensino. Como perspectiva dessa proposta, deseja-se que haja uma constituição de saberes que envolve emoções e técnicas de uma tradição que podem reverberar no contexto dos trabalhos artísticos na atualidade.

$\mathrm{Na}$ constante produção simbólica elaborada pelo homem em suas relações sociais, o fazer artístico, por meio do corpo, indiscutivelmente é um dos mais presentes diante das diversas linguagens existentes em nossos processos de cognição. A exploração corpórea como forma de comunicação humana se dá constantemente desde que sabemos da nossa existência. A partir desta constatação, várias performances populares que vemos em diversas comunidades brasileiras apresentam características das expressões ritualísticas e espetaculares advindas de etnias negras africanas. Portanto, compreender essa construção histórica é fundamental para que possamos agregar os saberes da negritude que reverberam nas artes corpóreas de nossa sociedade contemporânea brasileira. Acredita-se que essas descobertas possam edificar processos de aprendizagens em sujeitos que possuem em sua cultura, traços dessa memória ancestral.

Portanto, para que possamos construir no intérprete cênico, em ambientes de aprendizagens, reflexões e descobertas de uma negritude histórica em nosso país, as manifestações cênicas tradicionais da cultura negra mostram-se como um ca- 
minho para um processo educativo do corpo. Um corpo que agrega saberes elaborados a partir das percepções que os fenômenos da tradição oferecem e que possibilita aprendizados ao intérprete da cena, vislumbrando uma educação estética e artística.

Refletir sobre as expressividades estéticas da tradição na atualidade é fator preponderante para que os processos de criações artísticas exerçam uma consolidação na memória de sua sociedade, sem que tais produções se esvaziem no decorrer da história. Assim, as criações artísticas em nossos dias atuais, cada vez mais estão abertas a propostas que colaborem para reflexões críticas e que sejam elementos que favoreçam uma amplitude de constituições de saberes.

O nosso corpo é o canal que permeia todas as formas de sentir. É por meio dele que os sentidos se manifestam proporcionando a percepção e o incorporamento dos códigos de fenômenos estéticos e transformando assim em saberes, conhecimento. Para Hühne (1994) o fenômeno estético gera conhecimento a partir da experiência estética vivenciada pelo indivíduo. Neste sentido, em nossas decobertas, teremos a referêcia das matrizes corpóreas de tradição afro-brasileira. Essas matrizes serão o fenômeno estético que nos propiciará chegar a possíveis saberes elaborados por esses grupos étnicos advindos da diáspora negra africana.

Para a condução de um trabalho que envolva o aprendizado de culturas afrodescendentes e que reverbere em produção artística cênica, os saberes edificados a partir das percepções na vivência com as expressões de danças afro-brasileiras e a história documentada desses povos, dialogarão com os conhecimentos da contemporaneidade. Desta forma, será um caminho que permitirá probabilidades de intertextos corporais em elaborações de propostas de natureza estético-artísticas com a intenção de criar, recriar e hibridizar novas texturas para a cena atual.

É possível que um corpo se identifique com as tradições das culturas de matrizes africanas a partir das experiências com estas expressividades de arte? As técnicas apreendidas em danças afro-brasileiras podem levar o sujeito a novas descobertas culturais e corpóreas, acrescentando para seu aprendizado o conceito de negritude e aceitando-o como elemento de discurso social? Para essas indagações, digo que sim. Nós estamos aptos a reorganizar nossos conceitos e direcionar nossas experiências no intuito de aguçar e transformar nossos saberes. Obedecendo a dinâmica de transformações culturais, propagar saberes colabora com a manutenção da cultura, tal qual os negros escravizados tiveram que transformar a nova realidade como forma de resistência e afirmação constante, fazendo com que o legado cultural continue vivo em nossos dias. Assim, no ambiente de aprendizado artístico, ou outro qualquer, podemos mudar e revisar nossos procedimentos e saberes, algo que se faz urgente quando se trata de saberes afrorreferenciados.

Visto que nos fazeres africanos a técnica e a estética caminham juntas (LUZ apud SANTOS, 2002), essa visão se projeta, no âmbito do trabalho aqui exposto, resultante de pesquisa doutoral com discentes de graduação, negros e brancos, de classes sociais diversas, entre 18 e 25 anos. As técnicas vivenciadas na metodologia aplicada e as discussões envolvendo a temática da negritude fizeram perceber atitudes e reflexões que, por meio do corpo, revelam a compreensão do universo da cultura ancestral que envolve a cultura de afrodescendência.

Neste instante, enfatizo a ideia de negritude que permeia essa discussão referenciando Kabengele Munanga (2020) quando diz que, embora tenha origem com pessoas de cor de pele negra, não é meramente de ordem biológica. E destaca ainda que,

A negritude e/ou identidade negra se referem à história comum que liga de uma maneira ou de outra todos os grupos humanos que o olhar do mundo ocidental "branco" reuniu sob o nome de negros. A negritude não se refere somente à cultura dos povos portadores da pele negra que de fato são todos culturalmente diferentes. $\mathrm{Na}$ realidade, o que esses grupos humanos têm fundamentalmente em comum não é como parece indicar, o termo Negritude à cor da pele, mas sim o fato de terem sido 
na história vítimas das piores tentativas de desumanização e de terem sido suas culturas não apenas objeto de políticas sistemáticas de destruição, mais do que isso, de ter sido simplesmente negada a existência dessas culturas. (MUNANGA, 2020, p. 19)

Assim, o desejo da consciência da negritude a partir das experiências corpóreas, passa pela provocação e reflexão do papel que alunos/artistas possam ter diante da luta, resistência constante de valorização e visibilidade da cultura negra em nosso país.

Em minhas experiências com o grupo de discentes, ao pesquisar sobre práticas corporais para o trabalho do artista da cena se utilizando das danças afro-brasileiras, tais como; Maracatu e Maculelê ${ }^{2}$ a percepção dos alunos/artistas a comentarem a energia, os saberes apreendidos a partir destas formas de movimento refletidos no corpo, resultou no que denominei de "Corponegritude". Opto por criar um neologismo gramatical e proponho, ao longo da discussão o termo Corponegritude, tendo em vista que é a atitude despertada no sujeito, partícipe da experimentação, ao perceber-se um corpo com saberes constituídos a partir da experiência com a expressão de dança e os saberes da cultura afro-brasileira. As energias sentidas, as técnicas apreendidas, a nova visão de conceitos sobre a negritude, desencadeiam essa atitude corpórea para uma vivência da cultura negra em cena. O corpo experimenta a ação de estar em um estado de energia, tônus, de resgate de história. O corpo assume uma atitude do que reverberou como saberes e emitem-se em Axé.

O axé compreende-se como a energia viva, porém não estática. É a potência que fundamenta o acontecer, o devir. Essas dinâmicas de condução do axé se dão por meio de diferentes práticas rituais, e o axé é imantado tanto na materialidade quanto no simbólico, expressando-se como um ato de encante. (RUFINO, 2019, p. 67).

Estar-se-á considerando esse axé absorvido e

2 Tais danças revelam em suas histórias traços dos povos advindos da África negra e que se revelam como reflexo da memória ancestral, da história e estética destes. transmitido no corpo, construindo saberes efetivos. Assim, a Corponegritude é a atitude corpórea assumida pelos partícipes desta pesquisa, resultado do aprendizado técnico e estético em nossas atividades e transposto para a cena em forma de poiésis. Considerando a prática com um grupo de sujeitos com diversos tons de pele, contendo não negros, o foco na experiência do sentir, do vivenciar as premissas do universo de uma africanidade presente nas expressões da tradição trabalhada, é para onde corre esse entendimento. O conhecimento é sinestésico. São os saberes constituídos a partir da experiência do corpo e seus contextos históricos, dando consciência e importância para os valores da cultura negra em nosso legado.

Para que seja compreendido o Processo Cênico-pedagógico, adiante será apresentada a estrutura elaborada a partir da organização dos procedimentos metodológicos construídos em experimentos no espaço da sala de aula. O foco dessa exposição é mostrar a sistematização do caminho metodológico do processo, indicando para possíveis ações no espaço de ensino. Esses momentos foram experimentados durante elaboração de pesquisa e alterados de acordo com as reflexões e a necessidade de adaptação. As experimentações e os blocos de exercícios foram ganhando nomes. Assim, foi possível estabelecer um percurso que viabilizou a análise do movimento em processos de criação e como os corpos reagiam aos novos saberes advindos da prática com as expressões da tradição da cultura afro-brasileira.

Feitas as adaptações em exercícios e atividades para o enriquecimento metodológico, o caminho percorrido com os experimentos em sala de aula foi constituído por dois grandes Eixos e quatro momentos distintos (que chamarei de Eixinhos). Faz-se necessário deixar dito que a opção pelo termo Eixo vai ao encontro da arquitetura da cidade de Brasília, cidade em que a experimentação foi fundamentada. A cidade é dividida por duas rodovias que se cruzam e dão formato (de avião ou um pássaro) à cidade arquitetada por Oscar Niemayer e Lúcio costa, e estas são chamadas de Eixo monumental e Eixo rodoviário. 
Para fins de análises e discussões, dividi os procedimentos em dois grandes Eixos: Técnicol cinético e Poético/criativo. Os Eixos contemplados são dois grandes guarda-chuvas que se subdividem de acordo com os exercícios e atividades. As subdivisões que se complementam (Eixinhos), foram organizadas da seguinte forma: Sensibilização Motora (SM), Brincar com o Movimento (BM), Constituir Saberes (CS) e Projetar Saberes (PS). Para dar formato à estrutura metodológica neste processo cênico, o gráfico a seguir estabelecerá visualmente os eixos guiadores desta experiência.

Tabela 1 - Eixos guiadores do Processo Cênico Pedagógico
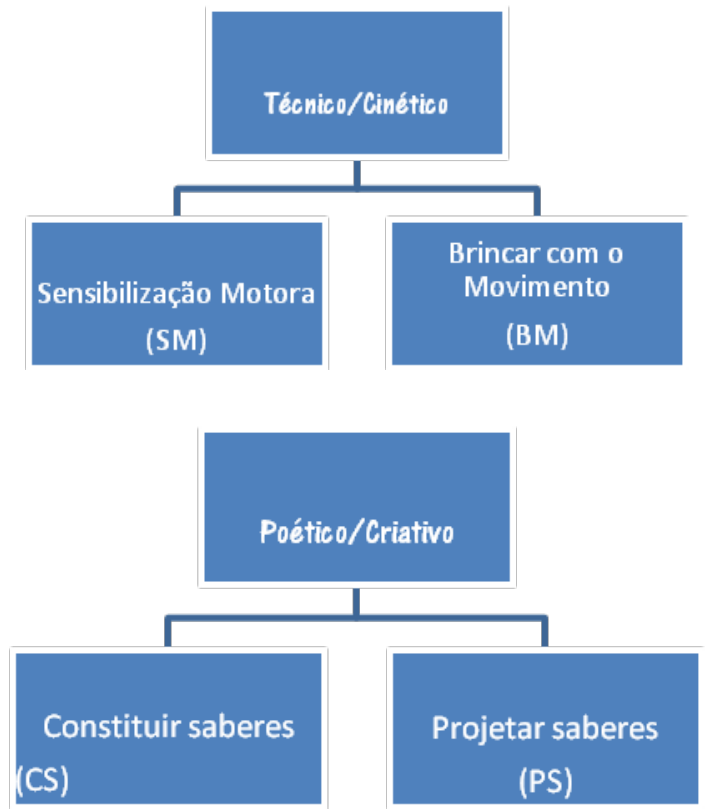

- A Compreensão Técnica/Cinética - Eixinho A Sensibilização Motora (SM)

Neste primeiro estágio do processo, a percepção cinética do movimento é base fundante. Tem-se a reflexão sobre as ações do corpo ao se movimentar no espaço. O foco deste Eixinho é revelar para o aluno/artista as necessidades e funções fisiológicas a partir da percepção dos músculos e ossos, da respiração e da força necessária (tônus) nessa ação. Busca-se permitir que os alunos/artistas envolvidos criem caminhos para que as ordenações do sentir o corpo sejam cabíveis de apreensão do mundo.

Esse estágio do trabalho é o instante do sen- tir o corpo, de perceber-se no espaço e descobrir sensações. Sugiro a busca da compreensão do movimento executado em seus aspectos técnicos, pensando sobre o que envolve as articulações corpóreas no ato de movimentar-se. Aqui, o sujeito é colocado para refletir sobre si no contexto "Eu corpo" e o seu funcionamento. É a técnica do movimento que será colocada no centro da reflexão.

Neste instante, proporcionei ao grupo de alunos/artistas o contato com a musicalidade do Maracatu, Maculelê, Jongo, Capoeira, para que tais ritmos fossem apreciados e sentidos no corpo como sendo um dos elementos estéticos a serem apreendidos pelo grupo. Os exercícios de consciência corporal partiram de matrizes de movimentos das danças elencadas, proporcionando a percepção técnica dos grupos musculares, de articulações, força, tenções necessárias para o desenvolvimento das ações com essas manifestações. Com isso, faz-se importante refletir que as características que estão contidas nas técnicas corporais dessas danças, levam para outros caminhos estéticos e revelam outras possibilidades de perceber o corpo à luz de heranças corporais de africanidades.

\section{- A Compreensão Técnica/cinética - Eixinho B - Brincar com o Movimento (BM)}

Exploradas as possibilidades técnicas/cinéticas no corpo, para dar continuidade à compreensão do Processo Cênico-pedagógico, é chegada a hora de brincar. Deixar a técnica se transformar em visceralidade, tornar entranhados os movimentos que, inicialmente, foram refletidos em seus percursos biofísicos. É hora de perceber as formas que os fenômenos estéticos, patrocinados pelas danças afro-brasileiras sugerem.

Nesse sentido, o Eixinho - Brincar com o Movimento (BM) insere o instante de brincar, compartilhar, inteirar-se com as descobertas realizadas. Refere-se ao estabelecimento da técnica do movimento percebida e o relaxamento do corpo em exprimir as impressões individuais ao dançar no espaço. Assim, é dada a hora de brincar, experimentar o festejo corpóreo por meio das movimentações que já fazem 
parte do conhecimento técnico do corpo. Em minha experiência, foram feitas provocações nos sujeitos para que o sentir não se restrinja à técnica, e sim, ao prazer de vivenciar o corpo em deslocamento no espaço com os ritmos que as expressões da negritude expõem. Foram feitas no espaço da sala de aula, atividades que exploravam no corpo os ritmos estudados. Os alunos/artistas a partir dos movimentos apreendidos, dançavam, brincavam com as diversas possibilidades de exploração de tais movimentos. Promovi a vivência dançante em formatos individual, duplas, grupos com a musicalidade das danças afro-brasileiras como agregação ao conhecimento e provocação para o corpo. Neste momento da proposta, também conduzi o grupo para a apreciação dessas manifestações cênicas tradicionais através de vídeos e fotografias, alimentando assim, o contato visual e a agregação dos fundamentos técnicos e estéticos.

\section{- A reverberação Poética/Criativa - Eixinho C - Constituir Saberes (CS) \\ O momento de Constituição de Saberes (CS)} é a organização dos principais aspectos apreendidos pelos partícipes no que diz respeito às novas descobertas a partir da prática vivenciada. É um momento de exercitar o que foi apreendido no corpo, considerando a criação a partir de jogos de improvisações e elaboração de cenas-coreográficas $^{3}$. É o momento de exercitar a criação artística. Traz-se para o foco as danças afro-brasileiras como elementos agregadores da educação em Arte, favorecendo o aprofundamento da história sociopolítica que envolve esse grupo étnico. Estas se mostram como potencialidades de inspirações para reelaborações possíveis para a cena. Em minha prática com o grupo, foram feitas discussões a partir de textos que refletissem o fazer artístico em

3 A utilização desse termo se dá por não existir, nesse momento, uma palavra que identifique as situações de cena teatral e coreografia conjuntamente na mesma sequência de cena. Não considero, por exemplo, o termo Dança-teatro, inspirado no trabalho de Pina Bausch, adequada para tal situação, visto que, em nossa proposta, as linguagens se deram em momentos distintos, imbricados por elos. conexões com as temáticas que envolvem os povos africanos e sua diáspora como o racismo, preconceito, negritude, estéticas negras e direitos sociais.

Esse é o instante de elaboração, de ordenar os aspectos da percepção desenvolvidos no trabalho em busca de formas estéticas para uma projeção de cenas. Proponho que, ao aluno/artista seja dada a oportunidade de criar, errar, fazer e refazer propostas cênicas que favoreçam encontros e desencontros de ideias e que as reflexões sejam instauradas com o ensejo de traçar cruzamentos dos saberes constituídos. A partir das relações com o que foi apreendido, propõe-se uma seleção dos materiais necessários para o seu trabalho, organizando com pertinência a ordem dos desejos pessoais e coletivos, dando então, significações e coerências a sua criação artística.

\section{- A Reverberação Poética/Criativa - Eixinho D - Projetar Saberes (PS)}

O Eixinho Projetar Saberes (PS) tem como princípio guiador a criação e a exposição de produções estético-artísticas propostas pelos alunos/ artistas. É o instante em que a organização dos saberes apreendidos durante os momentos anteriores possa coadunar-se de forma coletiva (ou individual). O foco está no resultado da forma/estética de uma corporeidade que se apresenta a partir das matrizes negras experimentadas e constituídas no corpo, instituindo-se na memória corpórea. É o momento de revelar a Corpornegritude adquirida ao logo do processo. Revela-se os saberes da cultura afro-brasileira no corpo, mostrando assim, as reivindicações, a luta, os desejos, a estética de negritude presente em nossa história e sociedade.

O resultado, criação dos alunos/artistas, propõe uma educação por meio da percepção corpórea mediante uma perspectiva interdisciplinar em que se envolvem diversas áreas do saber artístico, filosófico, antropológico, histórico, dentre outras que possam agregar-se a ela, fruto das discussões realizadas ao longo dos encontros.

Portanto, as descobertas técnicas e estéticas promovidas nesta condução com as práticas dan- 
çantes, deverão chegar a momentos de exposição ao público, fruto do trabalho e reverberações que se caracterizaram pelo termo Corponegritude. Para o público, é ofertada a corponegritude como atitude corpórea do aluno/artista nos momentos em que ele revela o envolvimento "máximo" com as matrizes apreendidas, incorporadas e explicitadas em suas ações em cena. Diante disso, desejei que a poética expressada pelos sujeitos no espaço cênico fosse resultado de aprendizado e provocações advindos das matrizes e estéticas corpóreas de negritude, presentes nas danças afro-brasileiras. Assim, o sujeito partícipe, o aluno/artista, independente de sua cor de pele (visto que em nossas diversas salas de aulas temos grupos diversificados), assume uma consciência dos aspectos sociais, históricos e estéticos que envolve o significado de negritude. Em posse disso, que este possa apresentar como novas descobertas de sua corporeidade, os elementos apreendidos das manifestações cênicas das tradições negras.

Tomando como base os Eixinhos anteriores - Sensibilização Motora (SM), Brincar com o Movimento (BM) e Constituir Saberes (CS), neste estágio em que os saberes constituídos se projetam em forma de criação artística, revelar-se-á onde se pôde chegar com esse procedimento pedagógico. Há de se deixar evidenciado que o foco deste trabalho está no processo vivenciado pelos sujeitos envolvidos. Busca-se contribuir com o preenchimento de lacunas que perpassam o aprendizado do aluno/artista cênico no que concerne aos saberes da africanidade presente nas tradições brasileiras.

Com esse momento de criação, proponho, portanto, proporcionar aos alunos/artistas: a) permitir que a partir das propostas e colaboração de cada um, possam chegar a uma experimentação cênica que comunique as matrizes estudadas, revelando a cultura negra brasileira; b) proporcionar a reflexão entre as danças tradicionais e suas projeções para os palcos formais de arte; c) fomentar um "novo olhar" para a cultura afrodescendente brasileira e, consequentemente, para o nosso país; d) perceber o estado e estágio da Corponegritude que exercem enquanto vivenciam essas expressões; e) perceber o potencial político, estético, cultural e pedagógico que essas formas de manifestações cênicas tradicionais podem trazer em seus contextos.

A Arte produzida nas comunidades populares é viva, é transformadora e dinâmica. Ela reivindica e mostra, ainda, uma luta constante do povo negro brasileiro em querer ser ouvido e contemplado socialmente. A manutenção e recriação estética das Artes da tradição do povo pelos seus participantes é um ciclo que se movimenta em sentidos de idas e voltas e que, nessa dinâmica, percebemos que vão se mantendo presentes na contemporaneidade. A contribuição das experiências pessoais em diálogo com o coletivo, com novas mídias e informações, reinventa as expressões da vida em sociedade hoje. Não só na atualidade se pontua esse fato, mas essa dinâmica já foi observada por Edison Carneiro, em meados do século $X X$, ao dizer que "o povo atualiza constantemente as suas maneiras de ser e participa ativamente da vida social, utilizando todos os meios ao seu alcance para fazer ouvir as suas queixas e as suas esperanças" (CARNEIRO, 2008, p. 16).

Considero que a vivência com as danças de culturas tradicionais afro-brasileiras necessita tornar-se uma referência de educação em nossas instituições. É uma continuidade da libertação da expressão desses grupos historicamente marginalizados. A partir deste conhecimento, permite-se o exercício do respeito para com a diversidade presente na cultura brasileira e, dessa forma, desmistificam-se os conteúdos referentes à cultura afrodescendente (SANTOS, 2002). Estamos diante de um desafio no trabaIho da educação artística na cena atual, em busca de uma afirmação da estética afro-brasileira presente em nossas expressões de Artes tradicionais.

Em momentos que a discussão do racismo, do preconceito social são temas recorrentes, é indiscutível a importância de trazer a temática das estéticas de negritude para a roda de conversa na escola. Essa proposta construída em uma instutição de ensino de nível superior, com discentes mistos em cores, ideias e classe social, precisa se estender por outros 
níveis do ensino básico. É necessário refletir sobre negritude à luz de uma não caricatura midiática que se reduz a sofrimento e lamento histórico. Precisamos mostrar as festas, as cores, a sonoridade, o corpo em que essas formas de Artes se mostram. Assim, estaremos elucubrando a multiplicidade étnica advida dos diversos países africanos que se adaptaram e recosntruíram as novas realidades que lhe foram impostas. Precisamos provocar a troca de saberes.

Diante destas interrelações, consideraremos esta cultura negra como sendo reflexo de trocas de diversas etnias que chegaram em nosso solo e que se constituíram em uma cultura agregada de diversos saberes. Levando em consideração os prícípios de seus grupos, desta relação de troca e a fortificação de seus símbolos, diz Sodré.

Na cultura negra, a troca não é dominada pela acumulação linear de um resto (de uma diferença), porque é sempre simbólica e, portanto, reversível: a obrigação (de dar) e a reciprocidade (receber e restituir) são as regras básicas. É o grupo (concreto) e não o valor (abstrato) que detém as regras das trocas. (SODRÉ, 1983, p. 127).

Nesta direção em que trocar saberes favorece o fortalecimento do ser individual e coletivo, essa construção que possibilita a reciprocidade faz-se pertinente nos processos de elaborações artísticas. Tratando-se do conhecimento nas artes da cena em que o corpo é o elemento de troca e de experimentação, permitir-se vivenciar tradições culturais de matrizes negras africanas que simbolizam saberes ancestrais, é conhecimento que se agrega na constituição do cidadão.

$\mathrm{Na}$ relação do saber tradicional em diálogo com o artísta cênico atual, é necessário considerar as experiências a partir das sensações somáticas vivenciadas por cada um de nós. Acredita-se que este fato é sem dúvida um campo aberto para novas descobertas e apreensão de conhecimentos. Ao se dispor para sentir e perceber, o artísta estará apto a receber e sistematizar saberes. O corpo expande significados a partir das experiências contidas nele.
É necessário que tenhamos como referência o corpo como porta de entrada para o sentir. A partir das sensações provocadas por este sentir, poderemos nos processos educacionais, transformá-las em conhecimentos. Desse modo, abre-se possibilidades para que surjam nas criações estético-artísticas, novas perspectivas das leituras e compreensões das artes de matrizes negras. Vivenciar corporeidades da negritude que constitui nossa formação social é um processo que possibilita a organização do saber tradicional e o projeta para outros futuros.

O aluno/artista da cena deve estar em constante processo de diálogos com práticas que o favoreça em seu aprendizado. Ele deve construir a história de sua Arte se apropriando de recursos que deem suporte para o desenvolvimento do seu fazer estético-artístico. O aluno/artista da cena deve se apoderar de partes para construir o todo de sua interpretação. Morin contribui com essa reflexão ao dizer que,

O conhecimento das partes depende do conhecimento do todo, como o conhecimento do todo depende do conhecimento das partes. Por isso, em várias frentes do conhecimento, nasce uma concepção sistêmica, onde o todo não é redutível às partes. (MORIN, 2009, p. 88).

Neste sentido, reforça-se a importância de construirmos nossos percursos de criação a partir de seguimentos e experiências diversos para que se chegue a um resultado que aponte, como implicação de um corpo em cena, estas características de aprendizados. Que em nossos diversos espaços de ensino, organizemos, a partir das partes, o nosso sistema de códigos estético-artísticos para chegar a um todo como resultado do saber edificado. Portanto, Conhecer e trazer para si os saberes da arte afro-brasileira em nosso solo constituídos e que estão expostos em expressões tradicionais, será uma agregação de um objeto da natureza popular em um corpo sujeito que constrói significados a partir do seu sentir. 


\section{Referências}

CARNEIRO, Edison. Dinâmica do folclore. São Paulo: WMF Martins Fontes,

2008.

A sabedoria popular. São Paulo: WMF Martins Fontes, 2008.

HÜHNE, Leda Miranda. (Org.) Fazer Filosofia. Rio de Janeiro: UAPE, 1994.

MEIRA, Marly Ribeiro. Educação estética, arte e cultura do cotidiano. In.:

PILLAR, Analice Dutra. (Orgs.). A educação do olhar no ensino das artes. Porto Alegre: Mediação, 2001.

MORIN. Edgar. A cabeça bem-feita: Repensar a reforma, reformar o pensamento. $16^{a}$ ed. Rio de Janeiro. Bertrand Brasil. 2009.

MUNANGA, Kabengele. Negritude - Uso e sentidos. $4^{a}$ edição. Belo Horizonte: Autêntica. 2020.

PEREIRA, Amorim Mendes. África: para abandonar estereótipos e distorções. Belo Horizonte: Nandyala, 2012.

SANTOS, Inaycira Falcão. Corpo e ancestralidade: uma proposta pluricultural de dança-arte-educação. Salvador: EDUFBA, 2002.

PARÂMETROS CURRICULARES NACIONAIS: Artes. Brasília: Ministério da Educação, 1996.

PARSONS, Michel J. Mudando direções na arte contemporânea. In.: Conferência em: a compreensão e o prazer da arte, 1, 1998, Ohio/EUA, conferências, Ohio/EUA: [s.n] 1998.

PILLAR, Analice Dutra. A educação do olhar no ensino das artes. Porto Alegre: Mediação, 2001.
RIBEIRO, Ana Paula. GONÇALVES, Maria Alice Resende. (Org.) Diversidade e Sistema de ensino Brasileiro. Rio de janeiro: Outras Letras, Volume 2. 2012.

RUFINO, Luiz. Pedagogia das Encruzilhadas. Rio de Janeiro. Mórula editorial. 2019.

SALES, Jonas de L. Corporeidades negras em cena - um processo cênico-pedagógico em diálogos com a tradição e a contemporaneidade, p. 255. Tese (Doutorado em Arte) - Universidade de Brasília - UnB, Brasília, 2015.

SODRÉ, Muniz. A verdade seduzida - por um conceito de cultura no Brasil. Rio de Janeiro: Codecri, 1983.

Recebido: 08/01/2021

Aceito: 15/05/2021

Aprovado para publicação: 29/05/2021

Este é um artigo de acesso aberto distribuído sob os termos de uma Licença Creative Commons Atribuição 4.0 Internacional. Disponível em: http://creativecommons.org/licenses/by/4.0.

This is an open-access article distributed under the terms of the Creative Commons Attribution License 4.0 International. Available at: http://creativecommons.org/licenses/by/4.0.

Ce texte en libre accès est placé sous licence Creative Commons Attribution 4.0 International. Disponible sur: http://creativecommons.org/licenses/by/4.0. 